\title{
OCULAR TOXICITY OF INTRAVITREOUS TRANSFORMING GROWTH FACTOR-BETA 1
}

\author{
CHANPING LIANG ${ }^{1}$, GHOLAM A. PEYMAN ${ }^{1}$ and JAY FEDERMAN ${ }^{2}$ \\ New Orleans and Philadelphia
}

\begin{abstract}
SUMMARY
Purpose: To evaluate the ocular toxicity of intravitreous transforming growth factor-beta 1 (TGF- $\left.\beta_{1}\right)$.

Methods: Eyes of New Zealand white rabbits were injected intravitreally with TGF- $\beta_{1}$ in doses of $20,10,5$, 1 or $0.5 \mu \mathrm{g}$. Electroretinography and clinical examination were performed before and after the injection. At either 10 or 30 days after injection, the eyes were enucleated and examined histologically. The endothelium of fresh corneas, which had received $20 \mu \mathrm{g}$ TGF- $\beta_{1}$ or nothing, were checked 5 days after injection.

Results: Corneal opacity was caused by doses $\geqslant 10 \mu \mathrm{g}$ in 7 of 7 eyes; by doses of $5 \mu \mathrm{g}$ in 3 of 4 eyes; and by doses of $1 \mu \mathrm{g}$ in 1 of 4 eyes. Doses $\geqslant 5 \mu \mathrm{g}$ also caused pannus formation in 15 of 16 eyes. Ten days after injection there was some decrease in B-wave amplitude on electroretinography. Thirty days after injection the electroretinographic responses had recovered, except in the eyes injected with $20 \mu \mathrm{g}$ TGF- $\beta_{1}$, which still showed a decrease in step 1 . Histological examination of paraffin sections did not demonstrate significant change. Corneal thickness of the eyes receiving $20 \mu \mathrm{g}$ TGF- $\beta_{1}$ was twice that of the normal cornea and some corneal endothelial cells lost their hexagonal shape. Conclusion: TGF- $\beta_{1}$ injected intravitreally at doses $\geqslant 1 \mu \mathrm{g}$ is toxic to the cornea. Retinal function is only slightly disturbed by $20 \mu \mathrm{g}$ of TGF- $\boldsymbol{\beta}_{1}$.
\end{abstract}

Transforming growth factor beta (TGF- $\beta$ ), originally identified by its ability to induce the reversible transformation of non-neoplastic cells in culture, ${ }^{1.2}$ is a very important multifunctional regulator of cellular activity. The term 'multifunctional' implies that TGF- $\beta$ may either stimulate cell proliferation and growth, or inhibit cell proliferation and growth,

From: ${ }^{1}$ LSU Eye Center, Louisiana State University Medical Center School of Medicine, New Orleans, Louisiana; Wills Eye Hospital, Philadelphia, Pennsylvania, USA.

Correspondence to: Dr Gholam A. Peyman, LSU Eye Center, 2020 Gravier Street, Suite B, New Orleans, LA 70112-2234, USA. Fax: +1 (504) 568-6193. or have numerous other actions with little relationship to either of these two processes. ${ }^{3}$

TGF- $\beta$ has been identified in many normal tissues. ${ }^{4}$ Several growth factors closely related to TGF- $\beta$ have also been identified (TGF- $\beta_{1}$, TGF- $\beta_{2}$ and TGF- $\beta_{3}$ ). The growth factors comprising the TGF- $\beta$ family are now thought to have roles in embryological development and normal physiology, as well as in pathophysiology. TGF- $\beta$ is important to wound healing; it is probably a natural mediator of wound healing.

TGF- $\beta$ is diffusely distributed in the eye, in the aqueous humour,5.6 conjunctival stroma, ciliary body, ${ }^{7.8}$ the choroid and retina. ${ }^{9}$

TGF- $\beta$ is an important factor in many aspects, including the mediation of the healing process in ophthalmic surgery. ${ }^{10}$ In order to guide the clinical use of TGF- $\beta$, we tested the ocular toxicity of TGF$\beta_{1}$.

\section{MATERIALS AND METHODS}

\section{Drugs}

TGF- $\beta_{1}$ in $20 \mathrm{mM}$ acetate buffer with $0.5 \%$ gelatin (100 Bloom, type A) stabiliser $(100 \mu \mathrm{g} / \mathrm{ml})$ and diluent was obtained from Escalon Ophthalmics (Skillman, NJ). It was kept at $4{ }^{\circ} \mathrm{C}$ and prepared fresh before intravitreous injection. Five different doses $(20 \mu \mathrm{g}, 10 \mu \mathrm{g}, 5 \mu \mathrm{g}, 1 \mu \mathrm{g}$ and $0.5 \mu \mathrm{g})$ were used in this study.

\section{Intravitreous Injection}

Twenty-eight eyes of New Zealand white rabbits weighing $2-3 \mathrm{~kg}$ were used in this study. The rabbits were treated in accordance with the Association for Research in Vision and Ophthalmology Statement for the Use of Animals in Research and were kept on a 12-hour light/12-hour dark cycle.

The eyes were divided into six groups: group 1,7 eyes given $20 \mu \mathrm{g}$ TGF- $\beta_{1}$ in $0.2 \mathrm{ml}$ of the stock solution; group 2, 4 eyes given $10 \mu \mathrm{g}$ TGF- $\beta_{1}$ in 
$0.1 \mathrm{ml}$ of the stock solution; group 3, 4 eyes given $5 \mu \mathrm{g}$ TGF- $\beta_{1}$ in $0.1 \mathrm{ml}$ diluent; group 4,4 eyes given $1 \mu \mathrm{g}$ TGF- $\beta_{1}$ in $0.1 \mathrm{ml}$ diluent; group 5, 4 eyes given $0.5 \mu \mathrm{g}$ TGF- $\beta_{1}$ in $0.1 \mathrm{ml}$ diluent; and group 6,3 eyes given $0.1 \mathrm{ml}$ diluent as control.

The rabbits were anaesthetised with an intramuscular injection of a mixture of ketamine hydrochloride $(50 \mathrm{mg} / \mathrm{kg})$ and xylazine hydrochloride $(5 \mathrm{mg} / \mathrm{kg})$. The pupils were fully dilated with $2.5 \%$ phenylephrine hydrochloride. Before injection, the conjunctiva was sterilised with $5 \%$ povidone-iodine and then washed with balanced salt solution. Paracentesis was performed with a 30 gauge needle on a $1 \mathrm{ml}$ tuberculin syringe before intravitreal injection; $0.1-0.2 \mathrm{ml}$ of aqueous humour was drawn out. The different doses of TGF- $\beta_{1}$ or diluent were then injected into the approximate middle of the vitreous cavity through the pars plana using a 30 gauge needle on a $1 \mathrm{ml}$ tuberculin syringe with the bevelled side of the needle facing anteriorly. Two normal eyes were used for evaluation of the thickness of the cornea and endothelium.

\section{Electroretinography Test}

Both before and 10 and 30 days after intravitreal injection, electroretinography (ERG) tests were performed with LKC Technologies UTAS-E 2000 systems for steps 1, 2 and 4 . Pupils were dilated with $2.5 \%$ phenylephrine hydrochloride and $1 \%$ cyclopentolate hydrochloride. The rabbits were darkadapted for 20 minutes before tests. During tests the rabbits were anaesthetised as described previously; the eyes were numbed with $0.5 \%$ proparacaine hydrochloride. Unipolar contact lenses were placed on both corneas with some Goniosol ophthalmic solution (IOLAB Pharmaceuticals, Claremont, CA). The negative electrode was inserted subcutaneously in the middle of the forehead and the ground was clipped to the earlobe. Three sweeps were averaged for each step. Steps 1,2 and 4 were a scotopic white $24 \mathrm{~dB}$ single flash, scotopic white $0 \mathrm{~dB}$ single flash, and photopic white $0 \mathrm{~dB}$ single flash, respectively. After step 2 was performed, rabbits were given 3-5 minutes of light adaptation before proceeding to step 4 .

\section{Clinical Observation and Histological Examination}

Before injection of the drug, the eyes were examined with the indirect ophthalmoscope and slit lamp and were found to be normal. After injection, the eyes were checked every 2 or 3 days with the slit lamp and indirect ophthalmoscope. At either 10 days or 30 days after intravitreous injection the rabbits were killed with an intracardiac injection of $1 \mathrm{ml}$ pentobarbital. Twelve eyes were enucleated at 10 days; 10 eyes were enucleated at 30 days after injection. The eyes were fixed in 2\% paraformaldehyde and $3 \%$ glutaraldehyde after enucleation, and then processed for paraffin sectioning, stained with haematoxylin and eosin, and observed under a light microscope. Four eyes which received $20 \mu \mathrm{g}$ TGF- $\beta_{1}$ and two normal eyes were enucleated 5 days after injection; the corneas were removed with a small rim of sclera. The corneal thickness was compared grossly with the normal cornea. The corneal endothelium was stained with $0.5 \%$ trypan blue as described elsewhere ${ }^{11}$ and the morphology was evaluated under a light microscope.

\section{Clinical Findings}

\section{RESULTS}

Groups 1 and 2. Three days after injection, opacity began in the corneas of all the eyes which received $20 \mu \mathrm{g}$ or $10 \mu \mathrm{g}$ of TGF- $\beta_{1}$. Five days after injection, the corneas were diffusely opaque with moderate congestion of the conjunctiva and pannus around the limbus (Fig. 1). There was no discharge or corneal epithelium defect, and the anterior chamber and fundus were not visible. Ten days later, the corneas were still opaque and no view of the inside of the eye was possible. Two weeks later, corneal opacity had become mild, the fundus was visible, and the retina appeared normal. The cornea was still slightly opaque but the pannus had diminished 30 days later.

Group 3. Three of the 4 eyes which received $5 \mu \mathrm{g}$ TGF- $\beta_{1}$ had diffusely opaque corneas with pannus around the limbus; the pannus was less severe than that of the eyes which received $20 \mu \mathrm{g}$ of TGF- $\beta_{1}$. The fundus was not visible in these 3 eyes. The opaque corneas became clear, pannus diminished 2 weeks after injection, and the retinas appeared normal. One cornea remained clear throughout; the fundus was visible.

Group 4. In the 4 eyes which were injected with $1 \mu \mathrm{g}$ of TGF- $\beta_{1}, 1$ cornea was slightly opaque and the other 3 were clear without pannus formation. The fundus of 2 of 4 eyes was not visible during the first week after injection. One week later, the cornea became clear and the fundus was visible; the retina appeared normal.

Group 5. In the 4 eyes which received $0.5 \mu \mathrm{g}$ TGF- $\beta_{1}$ the corneas were clear (Fig. 2) after injection but the fundus was slightly hazy in 2 of 4 eyes because of the opacity of the vitreous during the first week after injection. One week later, the vitreous became clear, the fundus was visible and the retina looked normal.

Group 6. In the 3 eyes injected with $0.1 \mathrm{ml}$ diluent as a control, all the corneas were clear after injection; however, the fundus was not visible in 2 of 3 eyes during the first week after injection. One week later, the fundus became clear in all eyes.

The clinical findings are summarised in Table I. 


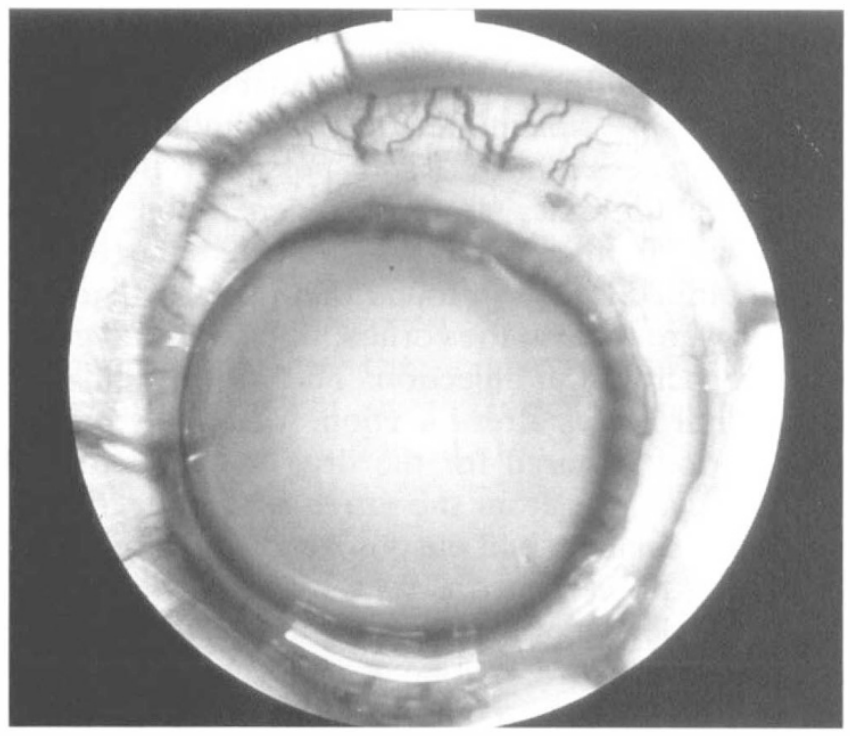

Fig. 1. Five days after injection of $20 \mu \mathrm{g} T G F-\beta_{1}$ the cornea is opaque with vessels around the limbus and congestion of conjunctival vesels.

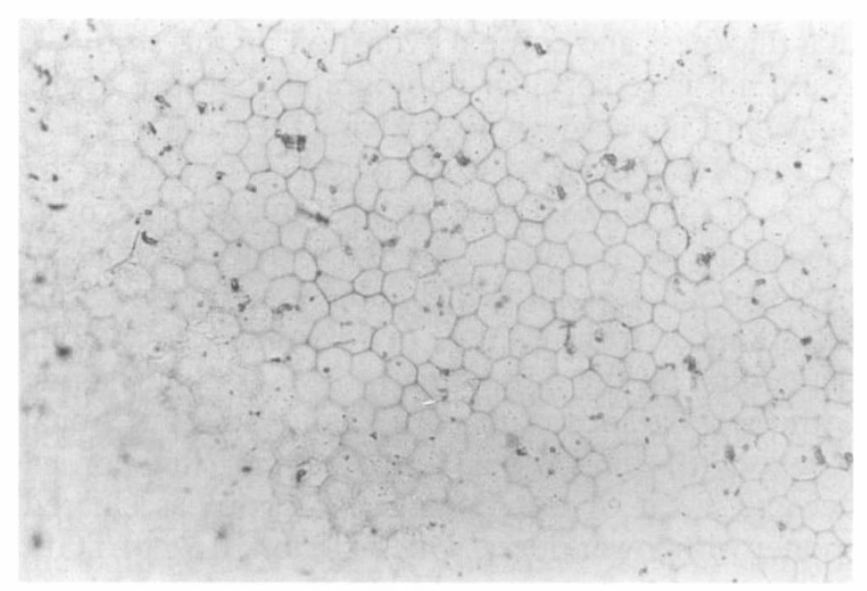

Fig. 3. The corneal endothelium showed a regular hexagonal shape (trypan blue stain, original magnification $\times 200$ ).

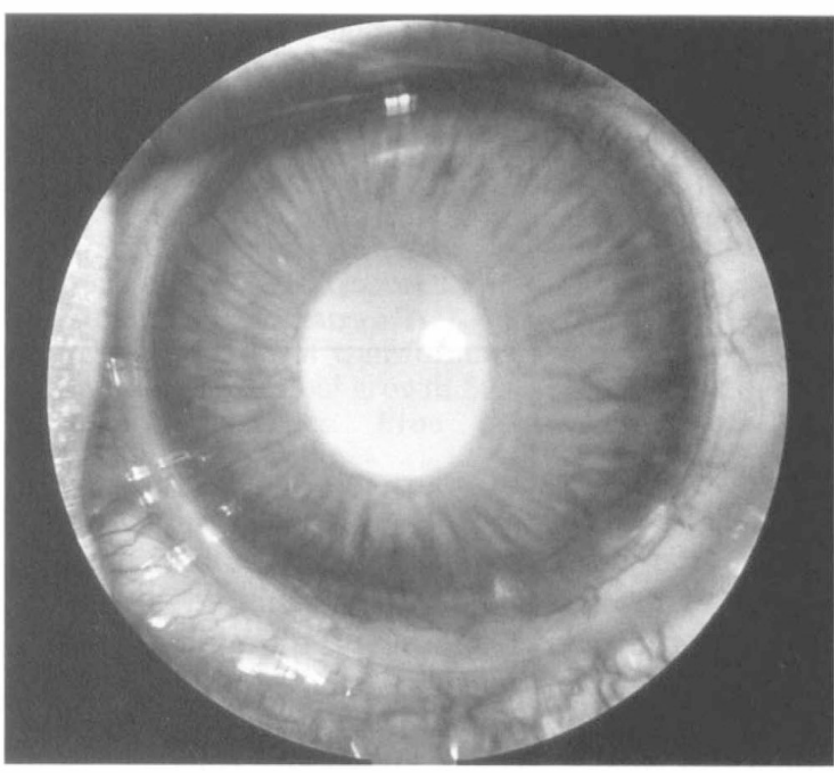

Fig. 2. Five days after injection of $0.5 \mu \mathrm{g}$ of $T G F-\beta_{I}$ the cornea is clear.

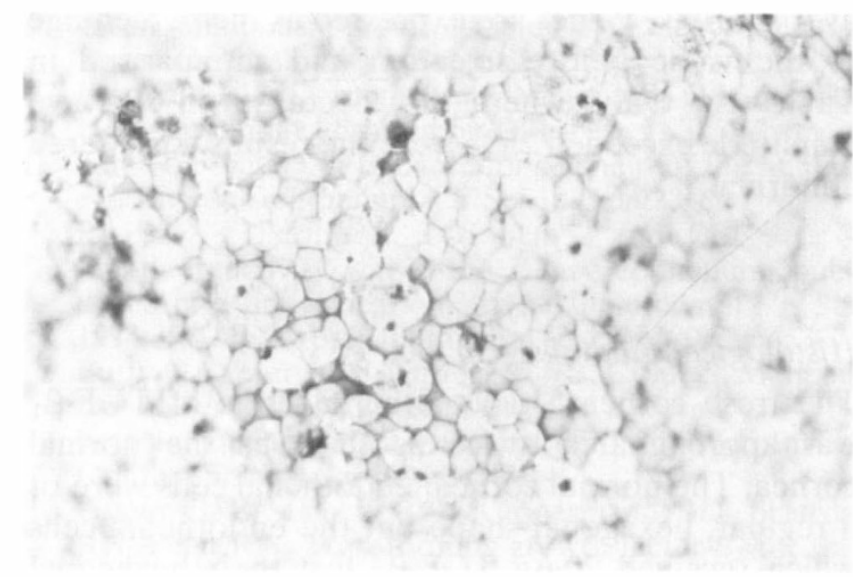

Fig. 4. The corneal endothelium 5 days after injection of $20 \mu \mathrm{g} T G F-\beta_{1}$. The corneal endothelial cells have lost their hexagonal shape, and they are enlarged and irregular (trypan blue stain, original magnification $\times 200$ ).

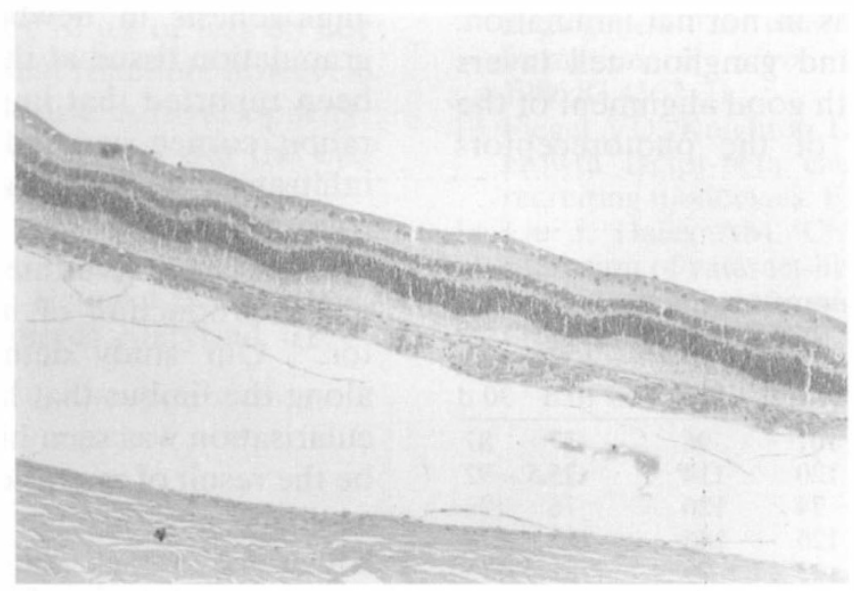

Fig. 5. Retinal section, 10 days after injection of $20 \mu \mathrm{g}$ $T G F-\beta_{1}$. The retina appears normal (haematoxylin and eosin stain, original magnification $\times 100$ ). 
Table I. Clinical findings after injection of TGF- $\beta_{1}$

\begin{tabular}{cccccc}
\hline Group & $\begin{array}{c}\text { No. of } \\
\text { eyes }\end{array}$ & $\begin{array}{c}\text { TGF- } \beta_{1} \\
(\mu \mathrm{g})\end{array}$ & $\begin{array}{c}\text { Corneal } \\
\text { opacity }\end{array}$ & Pannus & $\begin{array}{c}\text { Hazy } \\
\text { fundus }\end{array}$ \\
\hline 1 & 7 & 20 & $7 / 7$ & $7 / 7$ & $7 / 7$ \\
2 & 4 & 10 & $4 / 4$ & $4 / 4$ & $4 / 4$ \\
3 & 4 & 5 & $3 / 4$ & $3 / 4$ & $3 / 4$ \\
4 & 4 & 1 & $1 / 4$ & $0 / 4$ & $2 / 4$ \\
5 & 4 & 0.5 & $0 / 4$ & $0 / 4$ & $3 / 4$ \\
6 & 3 & Diluent & $0 / 3$ & $0 / 3$ & $2 / 3$ \\
\hline
\end{tabular}

\section{ERG Results}

A standard ERG protocol was used. This protocol is the one currently recommended by the International Society of the Clinical Electrophysiology of Vision. Step 1 is a rod response (dark-adapted, weak stimulus); step 2 is a maximum response to mixed rod and cone signals (dark-adapted, strong stimulus); step 4 is a single-flash cone response (light-adapted, strong stimulus).

The values of the B-wave amplitude before and after the injection were recorded for each group. The average ERG values are expressed as the percentage of the value before injection and summarised in Table II. Only when the decrease in B-wave amplitude exceeded $25 \%$ were the results considered abnormal.

\section{Histological Findings}

The fresh cornea 5 days after injection of TGF- $\beta_{1}$ was approximately twice as thick as the normal cornea. The normal corneal endothelial cells were of a regular, hexagonal shape but the endothelial cells which received $20 \mu \mathrm{g}$ TGF- $\beta_{1}$ lost their hexagonal shape and became irregular and enlarged (Figs. 3, 4). No significant difference was found in the corneal endothelium between the control and the treated group in paraffin sections. Although pannus was seen clinically, no neovascularisation was found histologically. The retina was in normal lamination. The outer, inner nuclear and ganglion cell layers were of normal thickness with good alignment of the inner and outer segments of the photoreceptors (Fig. 5).

Table II. Post-treatment ERG B-wave amplitude

\begin{tabular}{lrrrrrrrrr}
\hline & \multicolumn{2}{c}{ Step 1} & & \multicolumn{2}{c}{ Step 2 } & & \multicolumn{2}{c}{ Step 4 } \\
\cline { 2 - 3 } \cline { 8 - 9 } Group & $10 \mathrm{~d}$ & $30 \mathrm{~d}$ & & $10 \mathrm{~d}$ & $30 \mathrm{~d}$ & & $10 \mathrm{~d}$ & $30 \mathrm{~d}$ \\
\hline $1(20 \mu \mathrm{g})$ & 47 & 53 & & 101 & 96 & & 77 & 87 \\
$2(10 \mu \mathrm{g})$ & 108 & 161 & & 120 & 114 & & 75.5 & 92 \\
$3(5 \mu \mathrm{g})$ & 53 & 80 & & 74 & 126 & & 76 & 123 \\
$4(1 \mu \mathrm{g})$ & 83 & 137 & & 126 & 146 & & 103 & 179 \\
$5(0.5 \mu \mathrm{g})$ & 88 & 87 & & 113 & 99 & & 81 & 113 \\
6 (diluent) & 139 & 87 & & 209 & 125 & & 126 & 172 \\
\hline
\end{tabular}

Values are the percentage of preinjection readings.

$10 \mathrm{~d}, 10$ days after injection; $30 \mathrm{~d}, 30$ days after injection.

\section{DISCUSSION}

TGF- $\beta$ has multiple functions in ocular tissue, such as immunosuppression in the aqueous humour, ${ }^{5,6}$ modulating tissue repair, ${ }^{5,10}$ and possible effects on photoreceptor outer segment regeneration and/or function..$^{10}$ In this study, we evaluated the ocular toxicity of TGF- $\beta_{1}$. We found that doses of $1 \mu \mathrm{g}$ or greater were toxic to the cornea, which showed greywhite opacity after injection. The opacity did not occur until 3 days after injection, which may be the time period required for the drug to travel to the anterior chamber from the vitreous. The degree of opacity depended upon the dose: with $20 \mu \mathrm{g}$ or $10 \mu \mathrm{g}$ of TGF- $\beta_{1}$ the corneal opacity was severe; with lesser doses, the degree of the opacity and the frequency of incidence were lower. None of the eyes with opaque corneas had discharge and the intraocular pressure was within normal range, so we can exclude the possibility of glaucoma or infection.

The transparency of the cornea is maintained by the barrier function and active fluid pump of the corneal endothelium. Such functions maintain normal thickness and corneal hydration. In this study we could not take specular photographs because of the opacity of the corneas. In studying the fresh corneas, we found that there was a significant difference in the shape of the corneal endothelium and the thickness. Therefore, we postulate that the opacity was caused by disturbance of corneal endothelium function. This disturbance was totally or partially reversible, depending on the dose. One to 2 weeks later, along with the clearance of the drug and/or the functional recovery of the corneal endothelium, the cornea became clear, or less opaque. The corneas cleared sooner with lower doses; with $20 \mu \mathrm{g}$ or $10 \mu \mathrm{g}$ of TGF$\beta_{1}$ the opacity became mild but the cornea had not totally recovered 1 month after the injection.

Another change we found in the cornea after injection was pannus formation. TGF- $\beta_{1}$ was reported $^{12}$ to cause rapid induction of fibrosis and angiogenesis in newborn mice and formation of granulation tissue at the site of injection. It has also been reported that implantation of TGF- $\beta$ into the rabbit cornea can induce angiogenesis, white cell infiltration and corneal opacification. An indirect role for TGF- $\beta$ was postulated in angiogenesis through the recruitment of monocytes and subsequent production of a monocyte-angiogenesis factor. ${ }^{13}$ Our study demonstrated pannus formation along the limbus that later disappeared. No neovascularisation was seen histologically. The pannus may be the result of migration and dilatation of the limbal capillary net through the stimulation of TGF- $\beta_{1}$, which may reach the anterior chamber from the vitreous and leave the eye through the trabecular meshwork. Pannus formation was also dose dependent and reversible; with a $20 \mu \mathrm{g}$ dose the pannus 
was more vigorous than with lower doses. The pannus diminished 1-2 weeks after injection, which is similar to the results of the angiogenesis study by Roberts et al. ${ }^{12}$ in which the granulation almost totally disappeared after 5 days without injection of TGF- $\beta$. No white blood cell infiltration or neovascularisation in the eyes was found, possibly because we gave only a single injection.

In some rabbit eyes the fundus was not visible after injection of diluent only. However, in the eyes injected only with diluent, the corneas did not become opaque, leading to the conclusion that corneal opacity was caused by the TGF- $\beta_{1}$ and not the diluent; the diluent, however, may cause vitreous opacity and block the view of the fundus during the first week.

Retinal function was evaluated by the ERG response. Ten days after the injection there were some isolated decreases in the B-wave amplitudes in eyes that had received either high or low doses of TGF- $\beta_{1}$; there were no changes in the control. One month after the injection in group 1 eyes, there was still a $47 \%$ decrease in the B-wave amplitude in step 1 (weak stimulus, rod response), suggesting that rod function was affected to some degree; however, the responses to strong stimulus of both light- and darkadapted eyes were within normal limits. The eyes which received either $10 \mu \mathrm{g}$ TGF- $\beta_{1}$ or less or diluent did not show any decrease in ERG response 30 days after injection. The histology of the retina was normal.

In a study by Liu et al. ${ }^{14}$ lens explants from both postnatal and adult rats were placed in culture with growth factors for 5 days. TGF- $\beta$ induced epithelial cells in explants to undergo changes which resemble the pathological changes commonly seen in subcapsular cataracts. In this experiment we did not see changes in the lenses. This might be related to the absence of downregulatory mechanisms.

We conclude that TGF- $\beta_{1}$ injected into the vitreous at doses of $20 \mu \mathrm{g}$ may slightly disturb the function of the retina. Doses of $10 \mu \mathrm{g}$ or less do not significantly interfere with retinal function; however, doses higher than $1 \mu \mathrm{g}$ may cause corneal opacity. The diluent may cause vitreous opacity but the eye can recover spontaneously within 1 week.

Supported in part by US Public Health Service grants EY07541 and EY02377 from the National Eye Institute, National Institutes of Health, Bethesda, Maryland, USA.
Key words: Animal model, Cornea, Intravitreal injection, Retina, Toxicity, Transforming growth factor-beta 1 .

\section{REFERENCES}

1. Moses HL, Branum EL, Proper JA, Robinson RA. Transforming growth factor production by chemically transformed cells. Cancer Res 1981:41:2842-8.

2. Roberts AB, Anzano MA, Lamb LC, Smith JM, Sporn MB. New class of transforming growth factors potentiated by epidermal growth factor: isolation from nonneoplastic tissues. Proc Natl Acad Sci USA 1981;78:5339-43.

3. Sporn MB, Roberts AB, Wakefield LM, de Crombrugghe $\mathrm{B}$. Some recent advances in the chemistry and biology of transforming growth factor-beta. J Cell Biol 1987:105:1039-45.

4. Proper JA, Bjornson CL, Moses HL. Mouse embryos contain polypeptide growth factor(s) capable of inducing a reversible neoplastic phenotype in nontransformed cells in culture. J Cell Physiol 1982;110:169-74.

5. Jampel HD, Roche N, Stark WJ, Roberts AB. Transforming growth factor- $\beta$ in human aqueous humor. Curr Eye Res 1990;9:963-9.

6. Cousins SW, McCabe MM, Danielpour D, Streilein JW. Identification of transforming growth factor-beta as an immunosuppressive factor in aqueous humor. Invest Ophthalmol Vis Sci 1991:32:2201-11.

7. Pasquale LR, Dorman-Pease ME, Lutty GA, Jampel HD. Immunolocalization of TGF-beta 1, TGF-beta 2, and TGF-beta 3 in the anterior segment of the human eye. Invest Ophthalmol Vis Sci 1993;34:23-30.

8. Peress NS, Perillo E. TGF-beta 2 and TGF-beta 3 immunoreactivity within the ciliary epithelium [published erratum appears in Invest Ophthalmol Vis Sci 1994;35:4A]. Invest Ophthalmol Vis Sci 1994;35:453-7.

9. Lutty GA, Merges C, Threlkeld AB, Crone S, McLeod DS. Heterogeneity in localization of isoforms of TGFbeta in human retina, vitreous, and choroid. Invest Ophthalmol Vis Sci 1993;34:477-87.

10. Glaser BM, Michels RG, Kuppermann BD, Sjaarda RN, Pena RA. Transforming growth factor- $\beta_{2}$ for the treatment of full-thickness macular holes: a prospective randomized study. Ophthalmology 1992;99:1162-73.

11. Stocker FW, King EH, Lucas DO, Georgiade NA. Clinical test for evaluating donor corneas. Arch Ophthalmol 1970;84:2-7.

12. Roberts AB, Sporn MB, Assoian RK, et al. Transforming growth factor type $\beta$ : rapid induction of fibrosis and angiogenesis in vivo and stimulation of collagen formation in vitro. Proc Natl Acad Sci USA 1986;83:4167-71.

13. Fiegel VD, Knighton DR, Nelson RD. Transforming growth factor-beta causes indirect angiogenesis by recruiting monocytes. FASEB J 1988;2:1601.

14. Liu J, Hales AM, Chamberlain CG, McAvoy JW. Induction of cataract-like changes in rat lens epithelial explants by transforming growth factor beta. Invest Ophthalmol Vis Sci 1994;35:388-401. 